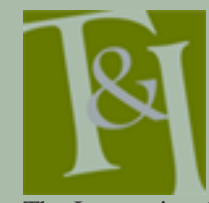

The International Journal for Translation \& Interpreting Research

trans-int.org

\title{
Signal Jamming in the Translation Market and the Complementary Roles of Certification and Diplomas in Developing Multilateral Signaling Mechanisms
}

\author{
Andy Lung Jan Chan \\ City University of Hong Kong \\ andyljchan@gmail.com
}

DOI: ti.105201.2013.a1

\begin{abstract}
The market for translation services provided by individuals is currently characterized by significant uncertainty because buyers lack clear ways to identify qualified providers from amongst the total pool of translators. Certification and educational diplomas serve to reduce the resulting information asymmetry, but both suffer from potential drawbacks: translator training programs are currently oversupplying the market with graduates who may lack the specific skills needed in the market and no certification program enjoys universal recognition. In addition, the two may be seen as competing means of establishing qualification. The resulting situation, in which potential clients are uncertain about which signal to trust, is known as a signal jam. In order to overcome this jam and provide more consistent signaling, translator-training programs and professional associations offering certification need to collaborate more closely to harmonize their requirements and deliver continuing professional development (CPD) that help align the outcomes from training and certification.
\end{abstract}

Keywords: certification, asymmetric information, signaling, signal jamming, academic degrees, continuing professional development (CPD)

\section{Introduction}

There is little doubt that the language services market (which includes translation and interpreting) is growing in importance. Though a recent survey on the status of the translation profession in the European Union (Pym, Grin, Sfreddo, \& Chan, 2012) claims that there are about 333,000 professional translators and interpreters in the world, the exact size and growth rate of the translator base are unclear. The increasing demand from a host of clients, ranging from financial companies to software developers, is more certain and has opened up many job opportunities for language service providers. However, we quite often hear people complaining about chaos in the translation market and poor translation quality. It is also sometimes said that it is difficult to find competent translators who can deliver a decent piece of work (in terms of quality, speed, and price). It is also reported that clients need to rely on reputation or word of mouth when finding new translators.

For many translation buyers, translation is more like an experienced good, distinguished by the fact that "its quality, and hence its value to consumers, cannot be precisely determined by buyers at the time of purchase" (Moav \& Neeman, 2004, p. 1). In view of this, reputation or word of mouth can to some extent act as a signaling device in the translation market. According to Shapiro (1983), for products where quality is difficult to 
observe prior to purchase, most buyers are willing to pay a premium for the seller's investment in reputation. However, reputation may only work well when the market concerned is small or highly regional. As the translation market has begun to operate on a more global scale, the cost of information and finding providers is on the rise, and there is a need for more effective signaling devices. Translator certification and university qualifications are sometimes suggested as better signals for the translation market than personal reputation.

Section 2 offers a brief definition of the terms asymmetric information, signaling, and certification. Section 3 discusses the recent boom in translator certification and examines under what situations translator certification may not function effectively as a signal. In Section 4 , the focus is on the signal device of a university degree or diploma, which is sometimes suggested as an alternative to translator certification. The problems associated with the use of the diploma as a signal are then discussed. The paper ends by suggesting how translator certification and university qualifications may complement each other to provide a more effective signal in the translation market.

\section{Asymmetric Information, Signaling and Certification}

Simply put, asymmetric information describes the prevalent human situations in which one party (the principal) has more or better information than the other (the agent). In a principal-agent arrangement, one person or entity acts on behalf of another. The former is called the agent and the latter is called the principal. This concept was first applied to the labor and education markets (Spence, 1973). In a job market, firms usually know less than workers do about workers' innate productivity. Some workers may wish to signal their ability to potential employers, and do so by choosing a level of education that distinguishes them from workers with lower productivity. Therefore, education is sometimes considered a signal. In this way, some information about the workers is conveyed to the employers.

More precisely, the signaling theory developed by Michael Spence $(1973,1974,2002)$ suggests that prospective employees possess two types of attributes: unalterable observed attributes (e.g., age and gender) and alterable attributes (e.g., level of education). Those alterable attributes are also called signals and are subject to change at the initiative of the individual. In fact, since the institutionalization of education in the modern era, education and the resulting academic qualifications and credentials have served as signals for organizations that make hiring decisions. Because employers do not have a real measure of knowledge, skills, and attitudes of job applicants, they use academic qualifications and other credentials as signals for making inferences about missing information (Barber, 1998).

Since corporations do not have a more accurate estimate of the future productivity of a potential employee, they may make the assumption that a potential employee who has a higher level of education possesses those qualities that may imply higher productivity. According to Benjamin, Gunderson, \& Riddell (1998, p. 322), employers use education to signal "unobserved ability" when screening employees. The signaling theories argue that individuals with higher ability are more likely to obtain higher levels of education than those with lower ability and that the level of educational attainment is a reflection of the inherent abilities of the individuals. 
The theories of signaling have been applied to selection scenarios that occur in a wide range of disciplines from anthropology to zoology (for a comprehensive review, see Bird \& Smith, 2005) and in the recent decade we have seen the application of asymmetric information and signaling in the industries of automobile insurance (Cohen, 2005), consumer credit (Karlan \& Zinman, 2009), nursing homes (Chou, 2002), organic food products (Giannakas, 2002) and real estate (Garmaise \& Moskowitz, 2004).

The concepts of asymmetric information and signaling can also be applied to the translation market. Due to regionalization and globalization trends, an increasing number of clients need translation services. However, because of the problem of asymmetric information, translation service buyers (principals) cannot effectively determine the quality of a translator (the agent), so some good translators may not get paid what they deserve. This has adversely affected the professional status of translators.

According to the Oxford English Dictionary, certification refers to "information making one certain of a fact, etc." In real life, certification is widely used in various markets such as organic agricultural products and the IT profession. In the translation market, certification can be provided by public authorities (e.g., sworn translators in continental law countries are certified by government agencies) or private bodies. And the latter can be further distinguished into first-party certification, second-party certification, and third-party certification (Washington \& Ababouch, 2011). This classification is further elaborated as follows:

- First-party certification. A single company or stakeholder group develops its own certification and is therefore self-declared.

Examples include the SDL Certification Program and translation tests administered by different translation companies.

- Second-party certification. An industry or trade association develops certification or standards. Examples include the certifications offered by the American Translators Association (ATA) and Chartered Institute of Linguists (CIoL) in the United Kingdom.

- Third-party certification. An accredited external and independent certification body that has no conflict of interest sets the standards for certification. At the moment, there is no such organization for the certification of translators.

\section{Translator Certification as a Signal: Scale Effect and International Collaboration}

In recent years, the issue of translator certification has attracted a great deal of attention among professional translators and even translation studies scholars. The European Commission has commissioned a study on the status of translators in the region and the resulting report (Pym, Grin, Sfreddo \& Chan, 2012) devoted a significant part of its discussion to signaling and certification. On the other hand, many countries have developed or are in the process of developing their own translator certification systems. Even older certification systems offered by well-established professional translator associations (e.g., ATA and CIoL) have introduced a number of new initiatives, such as mandatory continuing education requirements, to further develop their existing system. 
An important variable influencing the effectiveness and status of a professional association is its size. Sometimes the reputation of professional associations may bring economic benefits to the members. For example, according to empirical studies in auditing, members of internationally renowned accounting associations can command higher auditing fees than those of lesser-known accounting groups (Comunale \& Sexton, 2003). Of course, most professional associations of translators cannot claim to be large professional bodies if they are compared with professional associations in large, well-established professions such as accounting. The Association of Chartered Certified Accountants (ACCA), a British chartered accountancy body, has 140,000 members and 404,000 students. The number of members in each of the two major professional translator associations, ATA and CIoL, is less than one-tenth that of the ACCA: ATA has about 11,000 members in 90 countries, and CIoL has about 6,000 Fellows, Members, and Associate Members.

It may be superficial just to have a headcount, and the number of members is by no means the only way to judge the success or effectiveness of a professional association. However, it is possible that the more members a professional association has, the more likely it is to be recognized by its practitioners, other related professions, and the general public. In real life, it seems that professional associations of translators have the problem of "invisibility," as the various names may not necessarily be familiar to all language students, people responsible for hiring translators, and the general public. In a small-scale survey of 29 language students in the UK, it was found that less than one-fifth had heard of ITI (Institute of Translation and Interpreting) or CIoL (Leech, 2005). And in a study of translator recruiters carried out by this author, one of the interviewees, a client-relationship manager of a large multinational translation company, even had the misconception that "the only requirement to become a member of the Chartered Institute of Linguists is to pay a membership fee" (Chan 2009, p. 166). Therefore, we can say that the signaling effect of membership of a professional association of translators in general might not be very strong.

Having said this, closer and greater coordination among certification systems and professional organizations in different countries may achieve a scale effect on a regional or even an international level. On the education front, there have been a number of initiatives to harmonize translation degrees. A good example is the EMT (European Masters in Translation), a partnership project between the European Commission and higher-education institutions offering Master's level translation programs. The main goal of this project is to establish a quality label for university translation programs that meet agreed standards in education. University programs that are benchmarked to these standards become members of the EMT network. A similar initiative called TransCert has also been suggested for making translator certifications more portable within Europe or even on an international level (see the Budin, Krajcso, \& Lommel article in this issue). This initiative, if successful, may reach Level 4 in Van Damme's (2002) hierarchy for international collaboration for educational institutions (this

\footnotetext{
${ }^{1}$ Venuti (1995) who has popularized the term "invisibility" uses it somewhat differently. He applies the term "to describe the translator's situation and activity in contemporary Anglo-American culture" (p. 1). In short, this invisibility is produced by the way translators tend to translate "fluently" into English to produce an idiomatic target text.
} 
framework can also be used for illustrating the collaboration between professional bodies).

Van Damme's framework can be illustrated as follows:

\begin{tabular}{|l|l|}
\hline Level & Method of collaboration \\
\hline Level 4 & International certification \\
\hline Level 3 & Meta-certification \\
\hline Level 2 & Formal mutual recognition \\
\hline Level 1 & Informal exchange of information and best practices \\
\hline
\end{tabular}

Table 1. Van Damme's Hierarchy of International Collaboration in Professional Certification.

On Level 1, there is a minimal strategy to improve communication and exchange among national certification agencies that can act as a foundation for the harmonization and international benchmarking of trustworthy standards and methodologies. On Level 2, the strategy is to develop formal but "soft" mutual recognition based on a mutually accepted definition of concepts and basic standards and criteria. The strategy for Level 3 is the development of real meta-certification on an international scale, but Van Damme (2002) admits that "[T] here is no real significant example of this for the moment." Level 4 is the development of a real international certification agency. And Van Damme quite correctly warns that an international agency of this scale can be "very bureaucratic" and "costly". Nevertheless, the international professional translation community should strive in the future for collaboration at as high a level on the Van Damme scale as feasible, in order to maximize the recognition and value of translator certification.

\section{Education Qualification: An Alternative to Translator Certification as an Effective Signal?}

In my interviews with translator recruiters a few years ago, quite a number of informants stated that a university degree is the most important criterion for determining applicant suitability, and they "would be inclined to find a candidate with a degree in translation" (Chan 2009, p. 168). However, since the 1990s, there has been spectacular growth in the number of translator training institutions. In recent years, specialized Master's degrees in translation have also been mushrooming. According to Newmark's (2006, p. 186) observation,

[T]ranslation, particularly at postgraduate level, is thriving. Ten years ago there were about a dozen courses. Now [...]38 universities [in the United Kingdom] are "delivering" 76 courses, including audio-visual, screen, media and cultural transfer, translation and diplomacy.

Six years on, a recent survey of the translation-related courses in the UK by Riaz (2012) shows that there is a total of 85 such MA or MSc programs, representing an $11 \%$ increase in half a decade. Therefore, to some extent, it is fair to say that vocation-oriented degrees, such as an MA in Screen Translation Studies (University of Surrey, first offered in September 2004) and an MA in Legal Translation (City University of London, first offered in 
September 2008), are likely to compete with translator certification as a signaling device in the translation market.

Tan (2008) compares the cost of obtaining a translator certificate (in her case, ATA certification) and attending translation schools (Monterey Institute of International Studies), and finds that, although an MA degree costs a hefty US\$45,516, in the long run ATA certification can cost as much as, if not more than, that when the costs of Continuing Professional Development (CPD) over a specific period are included. Tan adds that ATA certification is limited in its global signaling power, as it is "only widely recognized in the US (and perhaps Canada), and that each country has its own certification system." Of course, a degree from the Monterey Institute can function quite effectively as a signal in the translation market, as the degree qualification has been in effect for more than 50 years and the entrance requirements are stringent. However, other translation schools vary considerably in admission standards and quality. To compete for students in order to maintain viability, they may oversupply the market with translators. Thus, in general, this uncertainty about qualification and oversupply makes it difficult for translators to convince clients to respect their educational credentials. Consequently, translators' control over their working conditions diminishes, and a vicious cycle of unprofessional behavior and mistrust by translation service buyers is initiated. This phenomenon is quite well documented in Tseng's (1992) analysis of the professionalization process of interpreters in Taiwan, and this may be applied to the translation profession.

The recent proliferation of MA translation programs has been a result of funding policies in higher education. In Britain, Rivza and Teichler (2007) point out that public policies in the UK of funding higher education in general as well as policies of not funding the majority of foreign students have led to a vested financial interest on the part of higher education institutions to attract foreign students paying higher fees. To make the matter worse, the Higher Education Funding Council for England has introduced a total spending cut of $£ 1,296$ million $(€ 1,620$ million) between the academic year 2011/12 and 2012/13 (Evans, 2012). Taking the MSc degree at Imperial College, London as an example, the tuition fee for British nationals and EU students will be $£ 7,000$ (approx. $€ 8,500$ ) a year for $2013-14$, but for overseas students it will be a hefty $£ 11,850$ (approx. $€ 14,000$ ). According to an email communication with Terri Jacques, the Course Administrator of the MSc Translation Program at Imperial College, for the 2007-08 academic year, the program had $14 \%$ non-EU international students, and the number for 200809 would be "at least double as [there is] a great increase in the number of international applicants." Whether these international translation students, after earning a Master's degree and returning to their home countries, can be equipped with a better signaling credential and have more success in the job market is questionable. The Master's programs in translation in the UK tend to be non-language specific, as they have to deal with many foreign languages. In addition, these programs focus on either translation technologies or academic translation studies and neglect translation skills. Prospective employers in the international students' home countries may have difficulty assessing exactly what skills graduates of these programs possess.

In summary, many translator recruiters still respect academic degrees as a signal mechanism in the job market, but translator training schools may be oversupplying the translation market with academic degrees. As a result the translation market continues to be flooded with translators with academic 
credentials of all levels. Employers need to have a clear idea of what a particular academic credential is signaling.

\section{Complementary Roles of Certification and Diplomas in Developing Multilateral Signaling Mechanisms}

The above discussion may illustrate the fact that there is currently a signaljamming problem in the job market for translators. In economics, a jam is defined as the inference problem faced by the decision-maker in an economic transaction (Fudenberg \& Tirole, 1986, p. 367). If academic qualifications and professional qualifications, such as certification, are viewed as being in competition with each other, it is more difficult for employers to make inferences about job applicants' employability from these credentials. Hence, there is a signal-jamming problem in the job market for translators.

At present, there seems to be a rigid demarcation between translator associations and translator training institutions. Traditionally, in the UK and many other countries, the connection is limited to two channels only. First, some translation departments are corporate members of professional translators' associations. For example, the MSc Translation Program of Imperial College, London, is a corporate member of ITI. Second, some universities and associations of professional translators have signed mutual recognition agreements regarding their certification examinations or degree programs. For example, holders of the Diploma in Translation will be granted exemption from Module 6 (Translation Project) of the MA in Translation Studies at Birmingham University, and students who attain a mark of $65 \%$ or more in the Annotated Translation Project of the MA in Applied Translation Studies at London Metropolitan University will be moderated by the CIoL Educational Trust with a view to granting exemption from Paper 2 or 3 (semi-specialized translation) of the Diploma in Translation.

However, as previously discussed, CPD (Continuing Professional Development) has become an increasingly important component of translator certification. Therefore there should be even closer collaboration between translator training institutions and professional translator associations. For instance, translator-training institutions can tailor better CPD programs in consultation with professional bodies and, as suggested by Cutler, "Translation courses... need to incorporate professional development features with the existing academic pathway" (2007, p. 5).

Translation companies, institutions that educate and train translators, and professional translator associations should engage in coordinated efforts to develop multilateral signaling mechanisms. Although in some countries and regions translation companies have their own association (e.g., Association of Translation Companies in the UK and European Union of Associations of Translation Companies), many professional translators' associations also accept corporate members (e.g., ITI and ATA), which can make communication and collaboration between the corporate world and professional translators easier. A logical development would be for companies, educational institutions, and professional associations to communicate regularly concerning real-life activities, academic programs, and CPD.

The above coordinated efforts will have two results. First, they can help foster trust in an increasingly uncertain translation market. Such trust significantly reduces asymmetric information in the translation market as the future perceptions of different parties about market uncertainty decrease. 
Second, translator training institutions and professional translators' associations will be more effective in circulating knowledge. The knowledge can be better diffused to all that can benefit, including professional translators, translation companies, and other stakeholders. In this way, it may be easier for employers to make inferences about job applicants' employability based on, e.g., CPD, and the process of recruiting translators can be easier, cheaper, and more time-efficient. Also, equipped with current knowledge and skills, translators will be better able to deal with change occurring in the translation industry.

None of the above means, however, that closer ties between training institutions and certification bodies are a panacea. There is a tale of caution to tell: in the translator market, certification and diplomas may serve to check and balance each other and too close a relationship between the two parties may actually weaken this check and balance effect. For example, the pass rate for the Diploma in Translation (a post-graduate qualification offered by the CIoL that may be taken by first-degree holders as well as anyone who is interested in becoming a member of the professional association) is generally believed to be around 30\%. The CIoL has ever announced a general pass rate for this examination, but it is perceived to be quite difficult (German Translation Tips \& Services, 2013). If university graduates from a translation program can be automatically exempted from the examination and thereby become a member of the organization, the signaling effect of this certification may well be weakened. Ideally, translator certification will be viewed as a valuable and desirable credential to be earned after a period of professional experience. The number of years of professional experience needed before obtaining certification should ideally be substantially less for a translator with an academic credential.

If certification is to be successful in the marketplace, it must demonstrate a clear signal to buyers of translation services. If certification is too easy or even automatic, its value will be unclear and buyers will seek other signaling methods. On the other hand, if it is too difficult or uncommon, it will not be recognized as an effective signaling device. The trick will lie in finding an acceptable balance that allows certification to avoid conflict (signal jamming) with other economic signals. 


\section{References}

Barber, A. E. (1998). Recruiting employees: Individual and organizational perspectives. Thousand Oaks, CA: Sage.

Benjamin, D., Gunderson, M., \& Riddell, C. (1998). Labour market economics (4th ed.). Toronto: McGraw-Hill.

Bird, R. B., \& Smith, E. A. (2005). Signaling theory, strategic interaction, and symbolic capital. Current Anthropology, 46(2): 221-48.

Budin, G., Krajcso, Z., \& Lommel, A. (2013). The TransCert Project: Ensuring that transnational translator certification meets stakeholder needs. Translation \& Interpreting, 4(2).

Chan, A. L. J. (2009). Effectiveness of translator certification as a signaling device: Views from the translator recruiters. Translation and Interpreting Studies, 4(2): 155-71.

Chou, S.-Y. (2002). Asymmetric information, ownership and quality of care: An empirical analysis of nursing homes. Journal of Health Economics, 21(2): 293-311.

Cohen, A. (2005). Asymmetric information and learning: Evidence from the automobile insurance market. Review of Economics and Statistics, 87(2): 197-207.

Comunale, C. L., \& Sexton, T. R. (2003). Current accounting investigation: Effect on Big 5 market shares. Managerial Auditing Journal, 18(6/7): 569-76.

Cutler, S. (2007). Bridging the academic and professional gap in translator training at Imperial College London. Presentation at the ITI $21 \mathrm{st}$ Birthday International Conference, London, United Kingdom, 21-22 April 2007. Retrieved from http://www.iticonference.org.uk/itic21/sessions/ITI_21st_Birthday_Conference_Cu tler_Redfern.pdf.

Evans, L. (2012, March 29). Higher education funding: Which institutions will be affected? The Guardian. Retrieved from http://www.guardian.co.uk/news/datablog/2012/mar/29/universityfunding-student-number-cuts.

Fudenberg, D., \& Tirole, J. (1986). A 'signal-jamming' theory of predation. The RAND Journal of Economics, 17(3): 366-76.

Garmaise, M. J., \& Moskowitz, T. J. (2004). Confronting information asymmetries: Evidence from real estate markets. The Review of Financial Studies, 17(2): 405-37.

German Translation Tips \& Services. (2013). Diploma in Translation. Retrieved from http://www.german-translation-tips-andresources.com/Diploma-in-Translation.html. 
Giannakas, K. (2002). Information asymmetries and consumption decisions in organic food product markets. Canadian Journal of Agricultural Economics, 50(1): 35-50.

Karlan, D., \& Zinman, J. (2009). Observing unobservables: Identifying information asymmetries with a consumer credit field experiment. Econometrica, 77(6), 1993-2008.

Leech, W. (2005). The translator's visibility: An investigation into public perception of the translator and how to raise the translator's status in society (Master's thesis). Retrieved from http://isg.urv.es/library/papers/leech_translator_visibility.pdf.

Moav, O., \& Neeman, Z. (2004). Inspection in markets for experience goods (Discussion Paper Series 349). Jerusalem: Center for Rationality and Interactive Decision Theory, Hebrew University. Retrieved from http://ratio.huji.ac.il/dp/dp349.pdf.

Newmark, P. (2006). Translation now-41. The Linguist, 45(6): 185-87.

Pym, A., Grin, F., Sfreddo, C., \& Chan, A. L. J. (2012). The status of the translation profession in the European Union. Luxembourg: European Commission.

Riaz, M. S. (2012).Translation-related courses in UK-based universities. Retrieved from http://translationstudiesinfo.blogspot.hk/2012/09/translation-relatedcourses-in-uk-based.html and http://translationstudiesinfo.blogspot.hk/2012/09/translation-relatedcourses-in-uk-based_17.html

Rivza, B.,\& Teichler, U. (2007). The changing role of student mobility. Higher Education Policy, 20: 457-75.

Shapiro, C. (1983). Premiums for high quality products as returns to reputations. Quarterly Journal of Economics, 98(4): 659-80.

Spence, A. M. (1973). Job market signaling. Quarterly Journal of Economics, 87(3):355-74.

Spence, A. M. (1974). Market signaling: Informational transfer in hiring and related screening processes. Cambridge, MA: Harvard University Press.

Spence, A. M. (2002). Signaling in retrospect and the informational structure of markets. American Economic Review, 92: 434-59.

Tan, Isabel. (2008). ATA: Access to translation agencies? Unpublished manuscript, Graduate School of Translation \& Interpretation, Monterey Institute of International Studies.

Tseng, J. (1992). Interpreting as an emerging profession in Taiwan: A sociological model (Master's Thesis). Fu Jen Catholic University, Taiwan.

Van Damme, D. (2002). Globalization and the market in higher Education: Quality, accreditation and qualifications. Paris: UNESCO: Editions Economica.

Venuti, L. (1995). The translator's invisibility: A history of translation. London: Routledge. 
Washington, S., \& Ababouch, L. (2011). Private standards and certification in fisheries and aquaculture: current practice and emerging issues. Rome: Food and Agriculture Organization. 